\title{
Quantitative assessment of myocardial motion from velocity encoded MRI
}

\author{
Anja Lutz ${ }^{1}$, Jan Paul ${ }^{1}$, Patrick Etyngier ${ }^{3}$, Axel Bornstedt ${ }^{1}$, Peter Bernhardt ${ }^{1}$, Gerd Ulrich Nienhaus², \\ Wolfgang Rottbauer ${ }^{1}$, Volker Rasche ${ }^{1 *}$ \\ From 15th Annual SCMR Scientific Sessions \\ Orlando, FL, USA. 2-5 February 2012
}

\section{Summary}

It is objective of this study to investigate the potential role of different automatically derived quantitative parameters derived from velocity encoded MRI for the identification of asynchronic patients.

\section{Background}

About $30 \%$ of patients treated with cardiac resynchronization therapy (CRT) do not benefit from the procedure. Quantitative analysis of motion encoded MRI data may provide helpful parameters for the identification of CRT patients and prediction of the therapy outcome.

\section{Methods}

11 Volunteers ( $30 \pm 8$ years) and 3 patients ( $41 \pm 11$ years) were investigated at a $3 \mathrm{~T}$ whole body MR scanner (Achieva, Philips) with a 32 channel cardiac coil. The patients suffered from DCM, asynchrony and/or LBBB. A velocity encoded (TPM) navigated segmented gradient echo sequence was applied in the apical, equatorial and basal slice. The acquisition parameters were: $F O V=340^{2} \mathrm{~mm}^{2}$, in-plane resolution $=2.5^{2} \mathrm{~mm}^{2}$, slice thickness $=8 \mathrm{~mm}$, acquisition matrix $\mathrm{MxP}=172 \times 168$, TR/ $\mathrm{TE}=6.3 \mathrm{~ms} / 4.6 \mathrm{~ms}, \alpha=15^{\circ}, 3 \mathrm{k}$-lines per segment, $\mathrm{VENC}=30 \mathrm{~cm} / \mathrm{s}$, nominal scan duration $=5: 51$ minutes, black blood imaging with alternating presaturation pulses [1] and a SENSE acceleration factor of 2. For $60 \mathrm{bpm} 32$ cardiac phases were measured with a phase interval of $29.1 \mathrm{~ms}$.

From the TPM data, the longitudinal and radial standard deviation of time to peak systolic and diastolic velocities $\mathrm{SD}\left(\mathrm{TTP}_{1, \text { sys }}\right), \mathrm{SD}\left(\mathrm{TTP}_{1, \text { dias }}\right), \mathrm{SD}\left(\mathrm{TTP}_{\mathrm{r}, \mathrm{sys}}\right), \mathrm{SD}$ $\left(\mathrm{TTP}_{\mathrm{r} \text {,dias }}\right)$ over 6 segments [2], the radial, circumferential and longitudinal asynchrony correlation coefficient (ACC) [3], the longitudinal and radial velocity range $\Delta v_{1}$ $=\mathrm{v}_{\mathrm{l}, \text { max }}-\mathrm{v}_{\mathrm{l}, \text { min }}, \Delta \mathrm{v}_{\mathrm{r}}=\mathrm{v}_{\mathrm{r}, \text { max }}-\mathrm{v}_{\mathrm{r}, \text { min }}$ and the temporal uniformity of velocity (TUV) in radial, longitudinal and circumferential direction were derived. The latter one was defined in analogy to the temporal uniformity of strain $[4,5]$.

\section{Results}

In all patients, a substantially detoriation of the motion curve from the healthy volunteers was observed (Figure 1). Most obvious, a clear reduction of the peak velocities can be appreciated.

The derived quantitative motion parameters are listed in table 1. All mean values of the derived parameters show differences between the patient and the volunteer group. $\Delta \mathrm{v}_{\mathrm{l}}$ and $\Delta \mathrm{v}_{\mathrm{r}}$ show large differences for all investigated motion directions, $\mathrm{SD}$ (TTP) appears increased, the mean ACC and the radial and longitudinal TUV reduced. Significances of the differences could not be calculated due to the small number of patients.

\section{Conclusions}

Several quantitative motion parameters show substantial differences between patients and volunteers and may be applied for automatic identification left ventricular asynchrony. Whether the investigated parameters can be applied for CRT patient selection and outcome prediction must be proven in a larger clinical study.

\section{Funding}

AL and VR have a research agreement with Philips Medical. PE is employed by Philips Healthcare. 

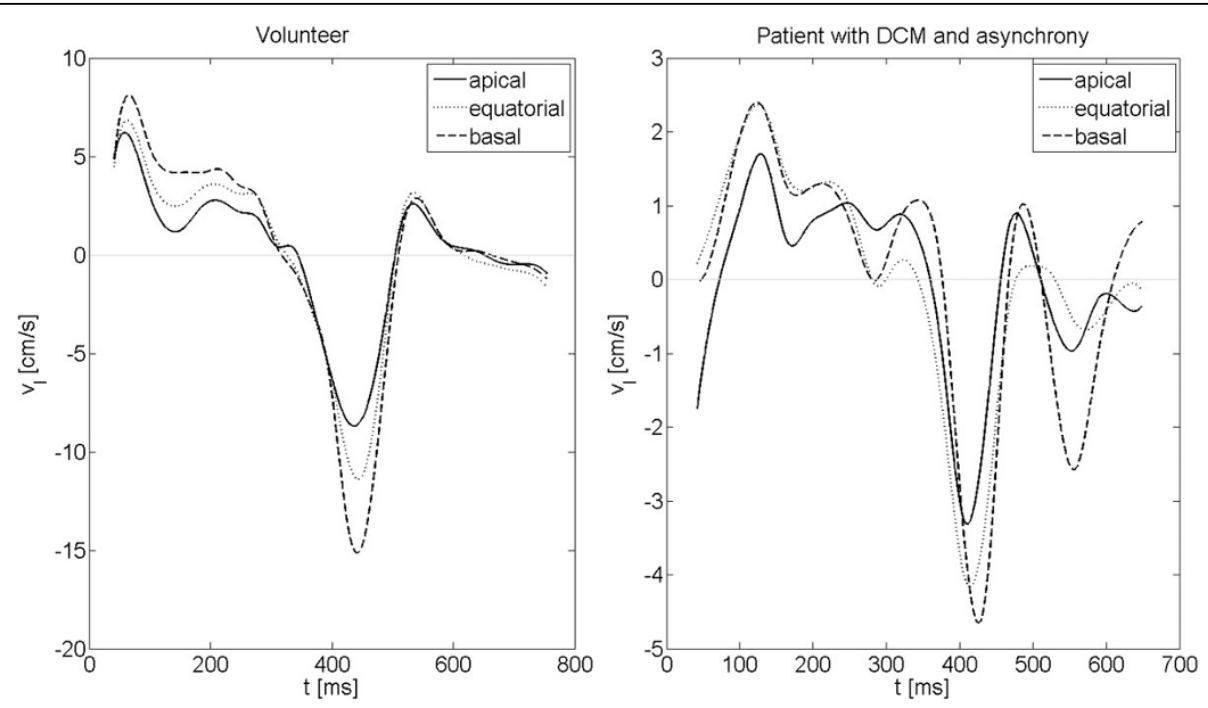

Figure 1 Apical, equatorial and basal longitudinal motion exemplarily for one volunteer.

Table 1 Velocity based motion parameters evaluated for all volunteers (mean \pm standard deviation) as well for the 3 investigated patients.

\begin{tabular}{|c|c|c|c|c|}
\hline \multirow[b]{2}{*}{ parameter } & \multicolumn{2}{|c|}{ volunteers } & \multicolumn{2}{|c|}{ patients } \\
\hline & mean & $\sigma$ & mean & $\sigma$ \\
\hline $\mathrm{SD}\left(\mathrm{TTP}_{\mathrm{I}, \mathrm{sys}}[\mathrm{ms}]\right.$ & 36.84 & 22.53 & 48.94 & 27.77 \\
\hline $\mathrm{SD}\left(\mathrm{TTP}_{\mathrm{l}, \mathrm{dias}}[\mathrm{ms}]\right.$ & 15.72 & 4.64 & 45.68 & 22.23 \\
\hline $\mathrm{SD}\left(\mathrm{TTP} \mathrm{P}_{\mathrm{r}, \mathrm{sys}}[\mathrm{ms}]\right.$ & 46.40 & 12.48 & 61.78 & 17.07 \\
\hline $\mathrm{SD}\left(\mathrm{TTP}_{\mathrm{I}, \text { dias }}[\mathrm{ms}]\right.$ & 33.85 & 8.75 & 49.75 & 21.39 \\
\hline mean $\mathrm{ACC}_{1}$ & 0.93 & 0.03 & 0.70 & 0.09 \\
\hline mean $\mathrm{ACC}_{\mathrm{r}}$ & 0.79 & 0.04 & 0.52 & 0.07 \\
\hline mean $\mathrm{ACC}_{\mathrm{c}}$ & 0.72 & 0.07 & 0.53 & 0.16 \\
\hline$\Delta \mathrm{v}_{\mathrm{l}, \text { apical }}[\mathrm{cm} / \mathrm{s}]$ & 10.77 & 2.19 & 5.12 & 1.37 \\
\hline$\Delta \mathrm{v}_{\text {l,equatorial }}[\mathrm{cm} / \mathrm{s}]$ & 16.13 & 2.54 & 7.14 & 3.27 \\
\hline$\Delta \mathrm{v}_{\mathrm{l}, \text { basal }}[\mathrm{cm} / \mathrm{s}]$ & 20.71 & 2.50 & 7.26 & 3.11 \\
\hline$\Delta \mathrm{v}_{\mathrm{r}, \mathrm{apical}}[\mathrm{cm} / \mathrm{s}]$ & 8.31 & 1.05 & 4.51 & 1.21 \\
\hline$\Delta \mathrm{v}_{\mathrm{r}, \text { equatorial }}[\mathrm{cm} / \mathrm{s}]$ & 7.97 & 0.97 & 4.26 & 0.40 \\
\hline$\Delta \mathrm{v}_{\mathrm{r}, \text { basal }}[\mathrm{cm} / \mathrm{s}]$ & 7.51 & 1.23 & 5.15 & 1.04 \\
\hline TUV & 0.87 & 0.02 & 0.78 & 0.04 \\
\hline $\mathrm{TUV}_{\mathrm{r}}$ & 0.80 & 0.02 & 0.70 & 0.02 \\
\hline $\mathrm{TUV}_{\mathrm{c}}$ & 0.77 & 0.03 & 0.69 & 0.06 \\
\hline
\end{tabular}

\section{Author details}

'Department of Internal Medicine II, University Hospital of UIm, UIm, Germany. ${ }^{2}$ Institute of Applied Physics and Center for Functional Nanostructures, Karlsruhe Institute of Technology, Karlsruhe, Germany.

${ }^{3}$ Medisys Research Lab, Philips Healthcare, Suresnes, France.

Published: 1 February 2012

\section{References}

1. Lutz, et al: MAGMA. 2011, 24(3):127-35

2. Föll, et al: J Magn Reson Imaging. 2011.

3. Schneider, et al: J Comput Assist Tomogr. 2001, 25:550-557.

4. Bilchick, et al: JACC Cardiovasc Imaging. 2008, 1:561-568.

5. Leclercq, et al: Circulation. 2002, 106:1760-1763.
doi:10.1186/1532-429X-14-S1-W39

Cite this article as: Lutz et al:: Quantitative assessment of myocardial motion from velocity encoded MRI. Journal of Cardiovascular Magnetic Resonance 2012 14(Suppl 1):W39.
Submit your next manuscript to BioMed Central and take full advantage of:

- Convenient online submission

- Thorough peer review

- No space constraints or color figure charges

- Immediate publication on acceptance

- Inclusion in PubMed, CAS, Scopus and Google Scholar

- Research which is freely available for redistribution

Submit your manuscript at www.biomedcentral.com/submit 